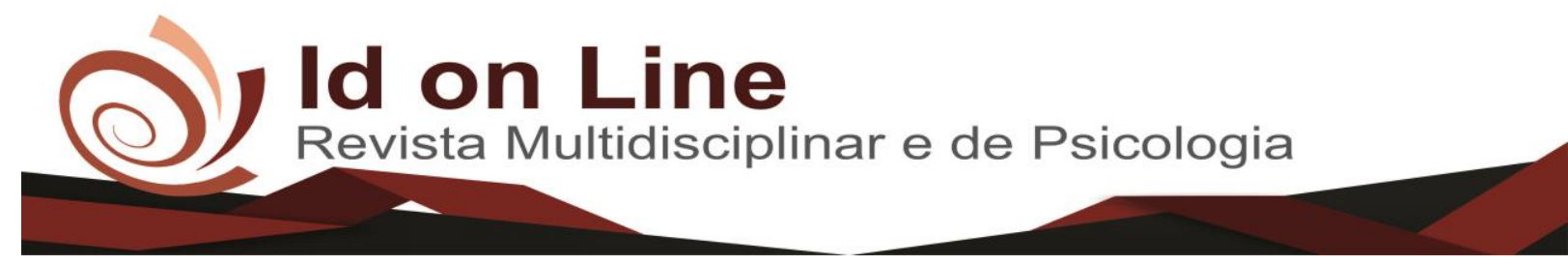

Artigo

\title{
Sistematização da assistência de enfermagem: revisitando a literatura brasileira
}

\author{
Renara Meira Gomes ${ }^{1}$; Lucas Silva Teixeira ${ }^{1}$; Maria da Conceição Quirino dos Santos ${ }^{2}$; \\ Zenilda Nogueira Sales ${ }^{3}$; Eliane Fonseca Linhares ${ }^{4}$; Kay Amparo Santos ${ }^{5}$
}

\begin{abstract}
Resumo: Objetivo geral: descrever as dificuldades encontradas pelos enfermeiros para implantação da sistematização da assistência de enfermagem nas unidades básicas de saúde e hospitalares a partir de estudos publicados em bases de dados. Método: uma revisão da literatura integrativa, utilizaram-se as seguintes etapas: delimitação do objetivo; definição dos critérios de inclusão das produções científicas; busca dos estudos nas bases de dados; análise dos resumos dos estudos; seleção dos estudos, de acordo com os critérios de inclusão; avaliação criteriosa e fichamento dos estudos selecionados e, por fim, a análise dos dados. Conclusão: Este estudo evidenciou contribuições significativas para serem refletidas pelos profissionais de enfermagem, especialmente os enfermeiros, ao apontar dificuldades que vem inviabilizando a implantação e implementação da SAE tanto nas unidades básicas como nas unidades hospitalares.
\end{abstract}

Descritores: Enfermagem; Processos de Enfermagem; Sistematização da Assistência.

\section{Systematization of nursing care: revisiting the brazilian literature}

\begin{abstract}
General objective: to describe the difficulties encountered by nurses to implement the systematization of nursing care in basic health and hospital units based on studies published in databases. Method: a review of the integrative literature, the following steps were used: goal delimitation; definition of the criteria for inclusion of scientific production; search for studies in databases; analysis of study summaries; selection of studies, according to the inclusion criteria; careful evaluation and registration of the selected studies and, finally, the analysis of the data. Conclusion: This study evidenced significant contributions to be reflected by nursing professionals, especially nurses, in pointing out difficulties that have made it un feasible to implement and implement SAE in both basic units and in hospital units.
\end{abstract}

Keywords: nursing; nursing processes; systematization of assistance.

${ }^{1}$ Graduandos em Enfermagem pela Faculdade de Tecnologia e Ciências de Jequié/Bahia. Endereço: Rua Antônio Orrico, 357, São José/Jequié/BA. E-mail: nara_rhema@hotmail.com, lucasteixeira20@gmail.com.

${ }^{2}$ Enfermeira, Doutoranda especial em Enfermagem e Saúde, Mestre em Terapia Intensiva, Professora da Faculdade de Tecnologia e Ciências de Jequié/BA. Endereço: Rua Candinha Barreto, 76. Jequiezinho. Jequié/BA, Brasil. E-mail: conceicaoquirino@gmail.com.

${ }^{3}$ Enfermeira, Doutora (Pós - doutora), Professora Plena departamento de Saúde II, Universidade Estadual do Sudoeste da Bahia/UESB. Endereço: Avenida José Moreira Sobrinho, SNº. Jequié/BA, Brasil. E-mail: zenysalles@ gmail.com.

${ }^{4}$ Enfermeira, Doutora, Professora Plena departamento de Saúde II da Universidade Estadual do Sudoeste da Bahia/UESB. Endereço: Rua Padre Altino Freire, 659. Centro. Jequié/BA, Brasil.E-mail: e-linhares@ bol.com.br.

${ }_{5}^{5}$ Enfermeira. Mestranda em Enfermagem e Saúde. Professora da Faculdade de Tecnologia e Ciências/FTC. Jequié (BA) Brasil. E-mail: kayamparo@hotmail.com

Autoria correspondente: Renara Meira Gomes. Rua Isaías Rêgo, 30, Centro. Dário Meira/BA.

E-mail: nara_rhema@hotmail.com 


\section{Introdução}

Para que a enfermagem se fortaleça cientificamente é preciso que ocorra algumas mudanças no seu pensar-fazer. Para tanto, o enfermeiro necessita planejar, refletir e justificar suas intervenções, a partir da Sistematização da Assistência de Enfermagem (SAE) (MARIA, 2012).

A SAE é um processo metodológico realizado apenas por enfermeiros com a finalidade de prestar cuidados de enfermagem de forma holística ao paciente, família e comunidade baseado no enfoque técnico-científico. A SAE tem como objetivo reduzir as complicações durante o tratamento, facilitar a recuperação e adaptação do paciente, família e comunidade, promovendo sua saúde e o seu bem-estar, sendo composta por cinco etapas: Coleta de dados e investigação; Diagnóstico de enfermagem; Planejamento da assistência; Implementação da assistência e Avaliação dos resultados (BRASIL, 2016).

Graças ao advento das teorias de enfermagem este cenário tem sido modificado, demonstrando que a enfermagem tem seus alicerces firmados na ciência, como primeiro exemplo podemos citar Florence Nightingale, sendo a primeira teórica de enfermagem a mostrar que o enfermeiro é capaz de oferecer melhorias ao paciente, colocando-o nas melhores condições para que a natureza aja através da modificação do ambiente interno e externo, satisfazendo, dessa forma, suas necessidades. Além disso, Florence ressaltou a importância da monitorização detalhada dos pacientes, do ambiente e seus registros para futuramente desenvolver conhecimentos acerca dos fatores que influenciavam na promoção da cura (CHAVES, 2009).

Nacionalmente, a teoria das necessidades humanas básicas desenvolvida por Wanda de Aguiar Horta é um dos modelos mais estudados e conhecido pelos docentes de enfermagem devido a sua utilização como suporte teórico (FIGUEIREDO, 2005).

Encontra-se disposto na Resolução COFEN no 358/2009 que a SAE é uma atividade privativa do enfermeiro, sendo um método científico que identifica as situações de saúde/doença, contribuindo junto com as ações de enfermagem para promoção, prevenção, recuperação e reabilitação da saúde do indivíduo, família ou comunidade. Além do mais, a SAE deve ser implementada em toda instituição de saúde, pública e privada, devendo ser formalmente registrada no prontuário do paciente, cliente ou usuário (CHAVES, 2009). 
Existem alguns modelos científicos que podem ser seguidos pelos enfermeiros que melhor orientam a sua prática, além de ser uma forma de universalizar a linguagem utilizada na SAE. As classificações são: North American Nursing Diagnosis Association - Diagnósticos de enfermagem da NANDA International (NANDA I) para as classificações dos diagnósticos de enfermagem; a Nursing Interventions Classification (NIC), para as intervenções de enfermagem e a Nursing Outcomes Classification (NOC) para os resultados de enfermagem (ALVES, 2013).

Em estudo realizado sobre a SAE, os autores revelaram que entre os anos de 1992 a 2002, 174 artigos foram publicados referente a esta temática. Ao se aproximar do ano de 2002 a média de publicações aumentou, chegando a 25 publicações neste mesmo ano. Identificaram, ainda, que das 174 publicações, 63,3\% se referia à área hospitalar e apenas 15,5\% à extrahospitalar (FIGUEIREDO, 2005).

Entretanto, mesmo que tenha aumentado o número de publicações, estudos evidenciaram que os enfermeiros apresentam dificuldades em suas práticas cotidianas de trabalho quanto à implantação da SAE de maneira integral. Dentre as dificuldades destacadas pelos enfermeiros, destacam-se a falta de recursos humanos, insumos, apoio institucional e gerencial que influenciam na operacionalização da SAE (ALVES, 2013).

Sabe-se que os enfermeiros de maneira geral, conhecem a SAE, algumuns possuem uma visão limitada e restrita, porém, tem outros que compreendem a SAE de maneira ampla e a consideram um instrumento de organização que facilita e dinamiza a assistência. Desta forma, aqueles que possuem uma visão simplificada e não a utilizam, precisam progredir quanto à sua implantação e implementação, pois a SAE é o método de organizar a assistência a ser prestada ao cliente, família e comunidade, permitindo a construção de um saber próprio e autônomo (VARELA, 2013).

O interesse na temática emergiu após vivência em estágios curriculares das disciplinas Supervisionado I e II, que compõem a matriz curricular do Curso de Graduação em Enfermagem da Faculdade de Tecnologia e Ciências (FTC), localizada na cidade de JequiéBA. Os estágios aconteceram numa Unidade de Saúde da Família (USF), num Hospital Público e numa Maternidade, nos quais foi observado que a SAE não é efetivada como dispõe a resolução COFEN n ${ }^{\circ} 358$.

Destaca-se que este é um estudo de grande relevância científica, pois acrescentará conhecimento à temática, subsidiando aos enfermeiros na implantação da SAE. 
A partir desse contexto surgiu a questão norteadora: quais as dificuldades encontradas pelos enfermeiros para implantação da SAE nas unidades básicas de saúde e hospitalares?

E, para responder a este questionamento, traçou-se como objetivo: descrever as dificuldades encontradas pelos enfermeiros para implantação da SAE nas unidades básicas de saúde e hospitalares a partir de estudos publicados em bases de dados.

\section{Metodologia}

Realizou-se uma revisão da literatura integrativa com objetivo de buscar, avaliar sintetizar e analisar estudos publicados em bases de dados nacionais que versam sobre as dificuldades dos enfermeiros na implantação da SAE.

Para tanto, segue-se as seguintes etapas: (1) Formulação da pergunta e objetivo da pesquisa; (2) Identificação das palavras-chave; (3) Definição de critérios para a inclusão e exclusão dos estudos; (4) Busca dos estudos nas bases/bancos de dados; (5) Categorização dos estudos; (6) Avaliação dos estudos incluídos; Interpretação e discussão dos resultados ${ }^{8}$.

A busca dos estudos nas bases de dados foram realizada entre janeiro e fevereiro de 2016 nas Bases de Dados da Biblioteca Virtual de Saúde (BVS) e na biblioteca Scientific Electronic Library Online (SciELO), utilizando os descritores: Enfermagem e Processos de enfermagem.

Os critérios de inclusão foram: artigo disponível gratuitamente na íntegra; publicado entre 2005 a 2015; responder à questão e ao objetivo da pesquisa. Os critérios de exclusão foram: artigo repetido nas bases consultadas, computando-os apenas uma vez; que não fossem da língua portuguesa e não estivessem disponíveis gratuitamente.

Foram encontrados 164 artigos na base de dados Scientific Electronic Library Online (SciELO), porém ente 11 artigos atenderam aos critérios de inclusão e ao propósito da pesquisa; 62 na Biblioteca Virtual de Saúde (BVS), sendo apenas 01 foi incluído. Foi utilizado ainda, o Google Acadêmico, no qual foi possível encontrar 04 artigos. Após seleção dos artigos, realizou-se leitura criteriosa dos títulos e resumos. Aqueles que responderam à questão norteadora e objetivo foram inclusos nesta revisão, totalizando 16 artigos. 
Em seguida, realizou-se leituras exaustivas, com intuito de extrair dados para o preenchimento de um formulário de coleta de informações, contendo os seguintes tópicos: título, autor, ano de publicação, objetivos, metodologia, resultados e conclusões.

Finalmente, realizou-se leituras das informações extraídas dos artigos e contidas no formulário, com intuito de organizá-las para facilitar a interpretação crítica e reflexiva dos dados selecionados.

\section{Resultados}

Os dados serão apresentados por meio de quadro, com ordem cronológica crescente de publicação (Quadro I). O Quadro I apresenta os artigos que compuseram a amostra analisada neste estudo.

Quadro I - Caracterização dos artigos que compuseram a amostra, autor, título, resultados encontrados quanto aos objetivos e metodologia.

\begin{tabular}{|c|c|c|c|c|}
\hline N. & Autores/Ano & Título & Objetivos & Metodologia \\
\hline 1 & $\begin{array}{l}\text { Figueiredo et al } \\
(2005)\end{array}$ & $\begin{array}{l}\text { Caracterização da } \\
\text { produção do } \\
\text { conhecimento } \\
\text { sobre } \\
\text { Sistematização da } \\
\text { Assistência de } \\
\text { Enfermagem no } \\
\text { Brasil }\end{array}$ & $\begin{array}{l}\text { - Caracterizar a produção } \\
\text { científica nacional sobre o tema } \\
\text { SAE e visualizar tendências da } \\
\text { mesma. }\end{array}$ & 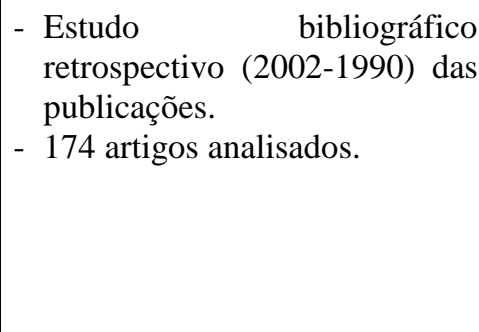 \\
\hline 2 & $\begin{array}{l}\text { Hermida e } \\
\text { Araújo (2006) }\end{array}$ & $\begin{array}{l}\text { Sistematização da } \\
\text { Assistência de } \\
\text { Enfermagem: } \\
\text { subsídios para } \\
\text { implantação }\end{array}$ & $\begin{array}{l}\text { - Identificar e refletir as fases } \\
\text { do planejamento para } \\
\text { implantação dessa prática, a } \\
\text { fim } \\
\text { de subsidiar a atuação do } \\
\text { enfermeiro nesse processo. }\end{array}$ & $\begin{array}{l}\text { - Estudo de revisão da literatura } \\
\text { nacional nas bases de dados } \\
\text { LILACS, } \\
\text { MEDLINE e BDENF. } \\
\text { - } 61 \text { artigos analisados. }\end{array}$ \\
\hline 3 & $\begin{array}{l}\text { Barros e } \\
\text { Chiesa (2007) }\end{array}$ & $\begin{array}{l}\text { Autonomia e } \\
\text { necessidades de } \\
\text { saúde na } \\
\text { Sistematização da } \\
\text { Assistência de } \\
\text { Enfermagem no } \\
\text { olhar da saúde } \\
\text { coletiva }\end{array}$ & $\begin{array}{l}\text { - Revisar os conceitos de } \\
\text { autonomia e necessidades de } \\
\text { saúde e suas aplicações nas } \\
\text { diferentes propostas de } \\
\text { sistematização da assistência de } \\
\text { enfermagem a fim de contribuir } \\
\text { com a nova visão de atenção à }\end{array}$ & $\begin{array}{l}\text { - Revisão bibliográfica sobre } \\
\text { sistematização da assistência de } \\
\text { enfermagem, autonomia e } \\
\text { necessidades de saúde nas bases } \\
\text { de dados LILACS e BDENF. } \\
\text { - Foram encontrados } 42 \text { estudos. }\end{array}$ \\
\hline
\end{tabular}




\begin{tabular}{|c|c|c|c|c|}
\hline & & & $\begin{array}{l}\text { saúde a partir da assistência de } \\
\text { enfermagem. }\end{array}$ & \\
\hline 4 & $\begin{array}{l}\text { Amante, } \\
\text { Rossetto e } \\
\text { Schneider } \\
(2008)\end{array}$ & $\begin{array}{l}\text { Sistematização da } \\
\text { Assistência de } \\
\text { Enfermagem em } \\
\text { Unidade de } \\
\text { Terapia Intensiva } \\
\text { sustentada pela } \\
\text { teoria de Wanda } \\
\text { Horta }\end{array}$ & $\begin{array}{l}\text { - Implementar a SAE, tendo } \\
\text { como referencial a teoria das } \\
\text { Necessidade Humanas } \\
\text { Básicas de Wanda de Aguiar } \\
\text { Horta e o Diagnóstico de } \\
\text { Enfermagem da NANDA, } \\
\text { partindo da avaliação do } \\
\text { conhecimento da equipe de } \\
\text { enfermagem sobre a SAE e } \\
\text { incluindo sua participação } \\
\text { nesse processo. } \\
\text { - Avaliar o conhecimento da } \\
\text { equi- pe de enfermagem } \\
\text { sobre a SAE e incluindo a sua } \\
\text { participa- ção nesse processo. }\end{array}$ & $\begin{array}{l}\text { - Pesquisa-ação de cunho } \\
\text { qualitativo. } \\
\text { - Referencial Teórico: Teoria das } \\
\text { Necessidades Humanas } \\
\text { Básicas de Wanda de Aguiar } \\
\text { Horta e o Diagnóstico de } \\
\text { Enfermagem da North } \\
\text { American Nursing Diagnosis } \\
\text { Association. } \\
\text { - Local: Unidade de Terapia } \\
\text { Intensiva de um Hospital em } \\
\text { Brusque, Santa Catarina. } \\
\text { - Informantes: } 2 \text { enfermeiros e } 8 \\
\text { técnicos. } \\
\text { - Técnica de coleta de dados: } \\
\text { entrevistas, } \\
\text { educativas e elaboração de } \\
\text { formulários. } \\
\text { - Técnica de análise de dados: } \\
\text { análise temática. }\end{array}$ \\
\hline 5 & $\begin{array}{l}\text { Garcia e } \\
\text { Nóbrega } \\
(2009)\end{array}$ & $\begin{array}{l}\text { Processo de } \\
\text { Enfermagem: Da } \\
\text { teoria à prática } \\
\text { assistencial e de } \\
\text { pesquisa }\end{array}$ & $\begin{array}{l}\text { - Fazer uma síntese da } \\
\text { evolução do conceito e } \\
\text { apresentar exemplos de estudos } \\
\text { em que se vinculam os } \\
\text { elementos da prática } \\
\text { profissional, inerentes ao } \\
\text { Processo de Enfermagem } \\
\text { (diagnósticos, intervenções e } \\
\text { resultados de enfermagem), à } \\
\text { investigação científica. }\end{array}$ & $\begin{array}{l}\text { - Relato de experiência - a autora } \\
\text { faz análise da evolução do } \\
\text { conceito do processo de } \\
\text { enfermagem e apresenta } \\
\text { exemplos de experiências quanto } \\
\text { a sua implantação. }\end{array}$ \\
\hline 6 & $\begin{array}{l}\text { Menezes, Priel } \\
\text { e Pereira } \\
(2011)\end{array}$ & $\begin{array}{l}\text { Autonomia e } \\
\text { vulnerabilidade do } \\
\text { enfermeiro na } \\
\text { prática da } \\
\text { Sistematização da } \\
\text { Assistência de } \\
\text { Enfermagem }\end{array}$ & $\begin{array}{l}\text { - Reconhecer a autonomia e a } \\
\text { vulnerabilidade do enfermeiro } \\
\text { no processo de implantação e } \\
\text { implementação da SAE. }\end{array}$ & $\begin{array}{l}\text { - Revisão bibliográfica } \\
\text { integrativa. } \\
\text { - } 40 \text { artigos encontrados. } \\
\text { - Técnica de análise: análise de } \\
\text { conteúdo. } \\
\text { (Artigo Original) }\end{array}$ \\
\hline 7 & $\begin{array}{l}\text { Silva et al. } \\
(2011)\end{array}$ & $\begin{array}{l}\text { O conhecimento } \\
\text { do enfermeiro } \\
\text { sobre a } \\
\text { Sistematização da } \\
\text { Assistência de } \\
\text { Enfermagem: da } \\
\text { teoria à prática }\end{array}$ & $\begin{array}{l}\text { - Analisar o conhecimento dos } \\
\text { enfermeiros sobre a } \\
\text { Sistematização da Assistência } \\
\text { de Enfermagem (SAE) em um } \\
\text { hospital de grande porte em } \\
\text { Recife, Pernambuco. }\end{array}$ & $\begin{array}{l}\text { - Estudo descritivo, exploratório } \\
\text { e quantitativo. } \\
\text { - Local: Hospital em Recife } \\
\text { - Informantes: } 107 \text { enfermeiros } \\
\text { - Técnica de coleta de dados: } \\
\text { questionário semiestruturado } \\
\text { - Técnica de análise de dados: } \\
\text { estatística simples }\end{array}$ \\
\hline
\end{tabular}




\begin{tabular}{|c|c|c|c|c|}
\hline 8 & $\begin{array}{l}\text { Varela et al } \\
(2012)\end{array}$ & $\begin{array}{l}\text { Sistematização da } \\
\text { Assistência de } \\
\text { Enfermagem na } \\
\text { estratégia saúde da } \\
\text { família: limites e } \\
\text { possibilidades }\end{array}$ & $\begin{array}{l}\text { - Identificar a concepção dos } \\
\text { enfermeiros sobre a SAE } \\
\text { enquanto instrumento } \\
\text { organização do trabalho } \\
\text { qualificação da assistência de } \\
\text { Enfermagem na Saúde da } \\
\text { Família e; } \\
\\
\text { - Identificar as dificuldades } \\
\text { encontradas para a efetivação } \\
\text { da Sistematização da } \\
\text { Assistência de Enfermagem na } \\
\text { Saúde da Família. }\end{array}$ & $\begin{array}{l}\text { - Pesquisa qualitativa do tipo } \\
\text { exploratória } \\
\text { - Sujeitos: enfermeiros das } \\
\text { Unidades Saúde da Família do } \\
\text { município de Mossoró, Brasil. } \\
\text { - Técnica de coleta de dados: } \\
\text { entrevistas } \\
\text { - Técnica de análise de dados: } \\
\text { por meio de categorias. }\end{array}$ \\
\hline 9 & $\begin{array}{l}\text { Maria, } \\
\text { Quadros e } \\
\text { Grassi (2012) }\end{array}$ & $\begin{array}{l}\text { Sistematização da } \\
\text { Assistência de } \\
\text { Enfermagem em } \\
\text { serviços de } \\
\text { urgência e } \\
\text { emergência: } \\
\text { viabilidade de } \\
\text { implantação }\end{array}$ & $\begin{array}{llr}\text { - Analisar a viabilidade } & \text { de } \\
\text { implantação da } & \text { SAE em } & \text { um } \\
\text { serviço de urgência } & \text { e } \\
\text { emergência hospitalar. } & \end{array}$ & $\begin{array}{l}\text { - Estudo de campo, descritivo, } \\
\text { qualitativo } \\
\text { - Local: hospital especializado } \\
\text { em atendimento de emergência. } \\
\text { - Informantes: oito técnicos de } \\
\text { enfermagem, dois auxiliares e } \\
\text { cinco enfermeiros } \\
\text { - Técnica de coleta de dados: } \\
\text { questionário não estruturado. } \\
\text { - Técnica de análise de dados: } \\
\text { Análise de conteúdo de Bardin }\end{array}$ \\
\hline 10 & $\begin{array}{l}\text { Medeiros, } \\
\text { Santos e Cabral } \\
\text { (2012) }\end{array}$ & $\begin{array}{l}\text { Sistematização da } \\
\text { Assistência de } \\
\text { Enfermagem na } \\
\text { perspectiva dos } \\
\text { enfermeiros: uma } \\
\text { abordagem } \\
\text { metodológica na } \\
\text { teoria } \\
\text { fundamentada }\end{array}$ & $\begin{array}{l}\text { - Compreender, a partir da } \\
\text { perspectiva dos enfermeiros, a } \\
\text { experiência de vivenciar a SAE } \\
\text { em um serviço de obstetrícia. }\end{array}$ & $\begin{array}{l}\text { - Tipo de estudo: estudo } \\
\text { descritivo, qualitativo na } \\
\text { perspectiva da teoria } \\
\text { fundamentada nos dados. } \\
\text { - Informantes: } 13 \text { enfermeiros } \\
\text { - Técnica de coleta dados: } \\
\text { observação participante, } \\
\text { entrevista semiestruturada e } \\
\text { oficina. } \\
\text { - Técnica de análise de dados: } \\
\text { codificação aberta, codificação } \\
\text { axial e codificação seletiva }\end{array}$ \\
\hline
\end{tabular}




\begin{tabular}{|c|c|c|c|c|}
\hline 11 & $\begin{array}{l}\text { Casafus, } \\
\text { Dell`Acqua e } \\
\text { Bocchi (2013) }\end{array}$ & $\begin{array}{l}\text { Entre o êxito e a } \\
\text { frustração com a } \\
\text { Sistematização da } \\
\text { Assistência de } \\
\text { Enfermagem }\end{array}$ & $\begin{array}{l}\text { - Compreender o processo } \\
\text { internacional planejamento- } \\
\text { execução da SAE de um } \\
\text { hospital universitário do } \\
\text { interior Paulista, na perspectiva } \\
\text { de dois grupos amostrais: } \\
\text { enfermeiros } \\
\text { técnicos/auxiliares } \\
\text { enfermagem, e desenvolver } \\
\text { uma síntese dos modelos } \\
\text { teóricos representativos dessas } \\
\text { experiências. }\end{array}$ & $\begin{array}{l}\text { - Pesquisa qualitativa } \\
\text { - Referenciais teórico- } \\
\text { metodológicos: Interacionismo } \\
\text { Simbólico e Grounded Theory } \\
\text { - Grupos amostrais: } 12 \\
\text { enfermeiros de } \\
\text { auxiliares/técnicos } \\
\text { enfermagem } \\
\text { - Local: hospital universitário } \\
\text { - Técnica de coleta de dados: } \\
\text { entrevista } \\
\text { - Técnica de análise de dados: } \\
\text { codificação aberta, codificação } \\
\text { axial e codificação seletiva. }\end{array}$ \\
\hline 12 & $\begin{array}{l}\text { Varela e } \\
\text { Fernandes } \\
\text { (2013) }\end{array}$ & $\begin{array}{l}\text { Conhecimentos e } \\
\text { práticas sobre a } \\
\text { Sistematização da } \\
\text { Assistência de } \\
\text { Enfermagem na } \\
\text { estratégia saúde da } \\
\text { família }\end{array}$ & $\begin{array}{lr}\text { - Identificar a compreensão dos } \\
\text { enfermeiros da Estratégia } \\
\text { acerca da Sistematização e } \\
\text { compreender } & \text { como } \\
\text { sistematizam a assistência de } \\
\text { enfermagem }\end{array}$ & $\begin{array}{l}\text { - Pesquisa qualitativa do tipo } \\
\text { exploratória. } \\
\text { - Local: USF do Município de } \\
\text { Mossoró, } \\
\text { - Informantes: enfermeiro que } \\
\text { atua na ESF } \\
\text { - Técnica de coleta de dados: } \\
\text { entrevista semiestruturada } \\
\text { - Técnicas de análise dos dados: } \\
\text { não explicita. Mas, foram } \\
\text { estabelecidas categorias. }\end{array}$ \\
\hline 13 & $\begin{array}{l}\text { Miranda et al. } \\
\text { (2013) }\end{array}$ & $\begin{array}{l}\text { Sistematização da } \\
\text { Assistência de } \\
\text { Enfermagem na } \\
\text { atenção primária à } \\
\text { saúde: um relato } \\
\text { de experiência }\end{array}$ & $\begin{array}{l}\text { - Criar estratégia para otimizar } \\
\text { o trabalho de enfermagem. } \\
\text { - Capacitar as enfermeiras para } \\
\text { o emprego das diversas } \\
\text { etapas da SAE, a partir de } \\
\text { casos clínicos especialmente } \\
\text { elaborados para as ESF's } \\
\text { - Cumprir com a normatização } \\
\text { estabelecida na Resolução do } \\
\text { Conselho Federal de } \\
\text { Enfermagem (COFEN) e a } \\
\text { solicitação do COREN-MG. }\end{array}$ & $\begin{array}{l}\text { - Estudo descritivo, tipo relato de } \\
\text { experiência, } \\
\text { - Realizado no Estágio } \\
\text { Curricular I - Internato Rural, } \\
\text { da Escola de Enfermagem da } \\
\text { Universidade Federal de Minas } \\
\text { Gerais-MG, Brasil, sobre a } \\
\text { implantação da SAE na } \\
\text { Atenção Primária à Saúde em } \\
\text { um município de Minas Gerais. } \\
\text { - Formulados impressos de } \\
\text { diagnósticos e prescrições de } \\
\text { enfermagem referentes à Saúde } \\
\text { do Adulto e do Idoso, à Saúde } \\
\text { da Criança e à Saúde da Mulher } \\
\text { visando implementar a } \\
\text { Sistematização da Assistência } \\
\text { de Enfermagem } \\
\text { - Realizada capacitação com as } \\
\text { enfermeiras para a utilização } \\
\text { dos mesmos. }\end{array}$ \\
\hline
\end{tabular}




\begin{tabular}{|c|c|c|c|c|}
\hline 14 & $\begin{array}{l}\text { Diniz et al. } \\
(2015)\end{array}$ & $\begin{array}{l}\text { Percepção dos } \\
\text { enfermeiros } \\
\text { gestores da } \\
\text { atenção primária } \\
\text { sobre o processo } \\
\text { de enfermagem }\end{array}$ & $\begin{array}{l}\text { - Analisar a percepção dos } \\
\text { enfermeiros gestores da } \\
\text { atenção primária à saúde sobre } \\
\text { o processo de enfermagem. }\end{array}$ & $\begin{array}{l}\text { - Estudo qualitativo } \\
\text { - Local: Secretaria Municipal de } \\
\text { Saúde (SEMUSA). } \\
\text { - Informantes: enfermeiros que } \\
\text { possuem cargos de gestão na } \\
\text { SEMUSA e que atuam na } \\
\text { atenção primária. } \\
\text { - Técnica de coleta de dados: } \\
\text { entrevistas } \\
\text { - Técnica de análise de dados: } \\
\text { análise de Conteudo Temática } \\
\text { Bardin. }\end{array}$ \\
\hline 15 & $\begin{array}{l}\text { Krauzer et al } \\
(2015)\end{array}$ & $\begin{array}{l}\text { Sistematização da } \\
\text { Assistência de } \\
\text { Enfermagem na } \\
\text { atenção básica: o } \\
\text { que dizem os } \\
\text { enfermeiros? }\end{array}$ & $\begin{array}{l}\text { - Identificar o conhecimento } \\
\text { que os enfermeiros da Atenção } \\
\text { Básica em Saúde, no Brasil, têm } \\
\text { sobre a Sistematização da } \\
\text { Assistência de Enfermagem. }\end{array}$ & $\begin{array}{l}\text { - Pesquisa descritiva } \\
\text { - Informantes: } 18 \text { enfermeiros } \\
\text { inseridos em unidades de saúde } \\
\text { da Região Oeste de Santa } \\
\text { Catarina. } \\
\text { - Técnica de coleta de dados: } \\
\text { entrevistas semiestruturadas } \\
\text { - Técnica de análise dos dados: } \\
\text { Análise Temática. }\end{array}$ \\
\hline 16 & $\begin{array}{l}\text { Souza et al } \\
(2015)\end{array}$ & $\begin{array}{l}\text { Sistematização da } \\
\text { Assistência de } \\
\text { Enfermagem: } \\
\text { dificuldades } \\
\text { referidas por } \\
\text { enfermeiros de um } \\
\text { hospital } \\
\text { universitário }\end{array}$ & $\begin{array}{l}\text { - Verificar dificuldades para } \\
\text { implementação da } \\
\text { Sistematização da Assistência } \\
\text { de Enfermagem. }\end{array}$ & $\begin{array}{l}\text { - Estudo descritivo } \\
\text { - Informantes: } 47 \text { enfermeiros } \\
\text { - Local: hospital universitário de } \\
\text { Recife/PE } \\
\text { - Técnica de coleta de dados: } \\
\text { questionário } \\
\text { - Técnica de análise dos dados: } \\
\text { estatística descritiva, com } \\
\text { cálculo de frequências } \\
\text { absolutas e relativas, } \\
\text { apresentados em tabelas. }\end{array}$ \\
\hline
\end{tabular}

Fonte: Pesquisa dos autores, 2018.

Dos 16 artigos que compuseram esta amostra, 06 foram desenvolvidos em unidade hospitalar e 06 em unidades básica de saúde, mostrando que a maioria dos enfermeiros que atuam nas redes básicas de saúde vem se empenhando no que se refere à implantação da SAE. Quanto aos demais, todos apresentam uma visão global sistematizada.

Quanto ao tipo de artigo publicado, 02 foram de relatos de experiências, 03 revisão de literatura e 11 foram artigos originais, embora desses 11 artigos, 01 artigo os autores descrevem e apresentam resultados de uma revisão bibliográfica integrativa. 
Quanto à metodologia, 02 utilizaram abordagem quantitativa e 14 a qualitativa. Em relação aos estudos com abordagem qualitativa, 01 apoiou-se no referencial teórico do Interacionismo Simbólico, 01 na Grounded Theory e 01 Teoria das Necessidades Humanas Básicas de Wanda de Aguiar Horta e o Diagnóstico de Enfermagem da North American Nursing Diagnosis Association. Os demais não utilizaram teorias para fundamentar os resultados. Para análise dos dados, a maioria utilizou a análise temática de conteúdo e dois se pautaram no referencial metodológico da Grounded Theory.

Quanto ao período de publicação relacionado ao número de artigos, foram verificados os seguintes registros anuais, em 2005 (1), 2006 (1), 2007 (1), 2008 (1), 2009 (1), 2011 (2), 2012 (3), 2013 (3) e 2015 (3). Observa-se que no período compreendido entre 2005 a 2009, o número de artigos publicados manteve-se na mesma proporção; em 2011 (2), o aumento de publicações duplicaram, exceto 2010, uma vez que não foi encontrado nenhum artigo. No ano de 2012 a 2015, o quantitativo de artigos publicados, apesar de ter ocorrido um pequeno aumento, também se manteve na mesma proporção.

Do total analisado, 10 dos artigos analisados tiveram como sujeitos de pesquisa enfermeiros e técnicos de enfermagem, 04 utilizaram bases de dados e 02 foram relatos de experiências, sendo que um deles se utilizou de bases de dados para discutir sobre a evolução do conceito de Processo de Enfermagem.

No que se refere ao meio de publicação 06 foram publicados na Revista da Escola de Enfermagem da USP, 02 Revista Brasileira de Enfermagem, 02 Escola Anna Nery Revista de Enfermagem, 01 na Revista da Rede de Enfermagem do Nordeste, 01 Revista Gaúcha de Enfermagem, 01 na Revista Cogitare Enfermagem, 01 Revista Ciencia y Enfermería XXI e 02 na Revista de enfermagem da UFPE on line .

No que se refere aos principais resultados e conclusões, os estudos foram agrupados em categorias temáticas, descritas no Quadro II. 
Quadro II - Consolidação dos resultados e conclusões dos estudos acerca das dificuldades encontradas pelos enfermeiros para implantação da SAE nas unidades básicas de saúde e hospitalares.

\begin{tabular}{|c|c|c|}
\hline Resultados & Conclusões & Autores \\
\hline $\begin{array}{l}\text { - Recursos humanos insuficientes } \\
\text { - Profissionais desmotivados e insatisfeitos } \\
\text { - Esgotamento fisico e psíquico dos } \\
\text { profissionais }\end{array}$ & $\begin{array}{l}\text { Reorganização dessa metodologia da } \\
\text { assistencial como prioridade } \\
\text { organizacional. Investindo em } \\
\text { educação permanente e um trabalho } \\
\text { de conscientização para que os } \\
\text { enfermeiros se envolvam no } \\
\text { processo de implantação da SAE. }\end{array}$ & $\begin{array}{l}\text { Souza de et al } \\
\text { Maria, Quadros } \\
\text { Grassi MFO } \\
\text { Casafus, Dell'Acqua e } \\
\text { Bocchi } \\
\text { Varela et al } \\
\text { Varela e Figueiredo } \\
\text { Garcia e Nóbrega et al } \\
\text { Silva EGC et al }\end{array}$ \\
\hline $\begin{array}{l}\text { - Recursos materiais insuficientes } \\
\text { - Ausência de recursos financeiros }\end{array}$ & $\begin{array}{l}\text { Flexibilização, agilidade gerencial e } \\
\text { assistencial para que a SAE seja } \\
\text { implementada gradativamente. } \\
\text { Oferta estrutural, organizacional e } \\
\text { orçamentário por parte institucional } \\
\text { que proporcione subsídos para a } \\
\text { aplicação da SAE. }\end{array}$ & Varela et al \\
\hline $\begin{array}{l}\text { - Diculdades de aceitação pela } \\
\text { equipe e falta de interesse dos profissionais }\end{array}$ & $\begin{array}{l}\text { Participação de toda a equipe de } \\
\text { saúde em um processo de trabalho } \\
\text { integrado. }\end{array}$ & $\begin{array}{l}\text { Miranda et al } \\
\text { Maria, Quadros e } \\
\text { Grassi }\end{array}$ \\
\hline $\begin{array}{l}\text { - Desconhecimento dos enfermeiros, } \\
\text { falta de capacitação, educação permanente e } \\
\text { continuada }\end{array}$ & $\begin{array}{l}\text { Refletir acerca da importância da } \\
\text { educação permanente nos serviços } \\
\text { de saúde, discutindo a SAE no } \\
\text { cotidiano da assistência e } \\
\text { direcionado para seu } \\
\text { desenvolvimento no exercício } \\
\text { profissional do enfermeiro. }\end{array}$ & $\begin{array}{l}\text { Miranda et al } \\
\text { Krauzer et al } \\
\text { Maria, Quadros e } \\
\text { Grassi }\end{array}$ \\
\hline $\begin{array}{l}\text { - Falta de tempo e mais impressos para serem } \\
\text { preenchidos }\end{array}$ & $\begin{array}{l}\text { Para que essas problemática seja } \\
\text { resolvidas propõe que acrescente } \\
\text { mais profissionais de enfermagem e } \\
\text { que o apoio da instituição é crucial } \\
\text { para a implementação da SAE. }\end{array}$ & $\begin{array}{l}\text { Miranda et al } \\
\text { Souza et al } \\
\text { Amante, Rossetto e } \\
\text { Schneider } \\
\text { Varela et al }\end{array}$ \\
\hline - Alta demanda de pacientes e famílias & $\begin{array}{l}\text { Articular estratégias e instrumentos } \\
\text { que viabilizem um caminho para } \\
\text { uma assistência diferenciada, } \\
\text { dinâmica e científica com a } \\
\text { visibilidade do saber/ fazer da } \\
\text { enfermagem e autonomia } \\
\text { profissional. }\end{array}$ & $\begin{array}{l}\text { Souza et al } \\
\text { Varela et al } \\
\text { Silva et al }\end{array}$ \\
\hline
\end{tabular}




\begin{tabular}{|c|c|c|}
\hline $\begin{array}{l}\text { - Discordância do aprendizado na graduação e } \\
\text { atuação na prática e abordagem nas escolas de } \\
\text { graduação insuficiente e/ou incoerente }\end{array}$ & $\begin{array}{l}\text { Intensificar o ensino do PE nas } \\
\text { escolas de graduação, bem como, na } \\
\text { área de atuação, na prática. Outro } \\
\text { ponto importante para implantação } \\
\text { da SAE é o interesse do professional } \\
\text { em aprofundar seus conhecimentos } \\
\text { sobre esse assunto e, buscar } \\
\text { estratégias para implantá- la. }\end{array}$ & $\begin{array}{l}\text { Miranda et al }{ }^{9} \\
\text { Krauzer et al }^{11}\end{array}$ \\
\hline - Método está voltado para a atenção terciária & $\begin{array}{l}\text { São necessários esforços e debates } \\
\text { no meio assistencial, gestão, ensino } \\
\text { e controle social, como propõem a } \\
\text { Política Nacional de Educação } \\
\text { Permanente, para o desenvolvimento } \\
\text { de aspectos primordiais na } \\
\text { qualificação da assistência em saúde, } \\
\text { especialmente no âmbito da AB, } \\
\text { como a SAE, entre outros recursos } \\
\text { emergentes. }\end{array}$ & $\begin{array}{l}\text { Krauzer et al } \\
\text { Gisele e Fernandes }\end{array}$ \\
\hline $\begin{array}{l}\text { - Falta de apoio e interesse por parte da } \\
\text { instituição em viabilizar e da gestão local em } \\
\text { implantar a SAE. }\end{array}$ & $\begin{array}{l}\text { Com a participação ativa dos três } \\
\text { pilares - órgãos legisladores de } \\
\text { enfermagem, gestão local de saúde e } \\
\text { governo Federal - a implementação } \\
\text { do PE seja viabilizada. }\end{array}$ & $\begin{array}{l}\text { Souza et al } \\
\text { Maria, Quadros e } \\
\text { Grassi MFO } \\
\text { Casafus, Dell'Acqua e } \\
\text { Bocchi SCM } \\
\text { Varela et al } \\
\text { Garcia TR, da Nóbrega } \\
\text { MML et al }\end{array}$ \\
\hline
\end{tabular}

Fonte : Levantamento dos autores, 2018.

No Brasil, a SAE ainda é uma área nova de conhecimento, apesar de ter sido divulgado principalmente por Wanda Horta que publicou em 1979 um livro intitulado O Processo de Enfermagem e somente recentemente o termo sistematização da assistência de enfermagem (SAE) foi incluído na (Decisão COREn-SP/DIR/ 008/1999) DECISÃO CORENSP/DIR/008/1999 - "Normatiza a Implementação da Sistematização da Assistência de Enfermagem - SAE - nas Instituições de Saúde, no âmbito do Estado de São Paulo. Entretanto, O Processo de Enfermagem é deveras complexo, assim como é complexa a noção do cuidado de enfermagem, apresentando dificuldades para sua implementação sistemática e efetiva pelos profissionais.

Estudos apontam que dentre as dificuldades, existem aquelas inerentes à formação dos profissionais, algumas referentes à organização do processo de trabalho, outras que dizem respeito às expectativas das instituições e outras referentes ao modo como a sociedade ou os 
gestores da saúde entendem o papel do enfermeiro e da equipe de enfermagem (GARCIA, 2009).

Destarte, a partir das leituras dos artigos selecionados neste estudo, foi possível observar que as principais dificuldades encontradas pelos enfermeiros para implantação da SAE foram: falta de tempo, mais impressos a serem anexados ao prontuário, falta de interesse, falta de conhecimentos dos enfermeiros e dificuldades de aceitação pela equipe multiprofissional, ensino do PE e SAE nas faculdades, falta de profissionais, alta demanda de pacientes, sobrecarga do enfermeiro, falta de capacitação e treinamento da equipe.

No estudo intitulado Entre o êxito e a frustração com a SAE, os autores identificaram que o déficit de recursos humanos e direcionamento adotado pela Instituição são as principais dificuldades encontradas para a implantação da SAE, impulsionando o enfermeiro a realizar uma SAE ilusória, e perpetuando um processo cíclico de sofrimento, por vivenciar a invisibilidade de sua práxis no processo de trabalho. É a decepção de não atingir o desejo de realizar a SAE conforme preconizada pela Lei do Exercício Profissional, ao deparar-se com a falta de apoio da Instituição. O déficit de recursos humanos, associado ao sentimento de culpa do enfermeiro por não realizar a SAE, constitui-se no principal componente que contribui para a invisibilidade de sua práxis e, consequentemente, do reconhecimento social da profissão e da preservação da saúde ocupacional (KRAUZER, 2015).

$\mathrm{Na}$ Unidade Hospitalar, há duas vertentes relacionadas às dificuldades encontradas pelos enfermeiros para implantação no hospital, a primeira é institucional (não implantação, falta de profissionais e alta demanda de pacientes) e a segunda são aquelas relacionadas ao profissional (falta de tempo e sobrecarga do enfermeiro, falta de capacitação e treinamento da equipe) (SOUZA, 2015).

Um estudo desenvolvido numa UTI acerca da implantação da SAE, identificou que os enfermeiros não sabiam utilizar os instrumentos pelo fato de não terem um contato prévio com os mesmos, além disso, os enfermeiros despendiam mais tempo realizando a SAE. A autora demonstra que não cabe apenas ao enfermeiro identificar o diagnóstico mas também relacionálo com as características definidoras e com fatores relacionados (AMANTE, 2009).

Pesquisadores procuraram analisar a viabilidade de implantação da SAE em um serviço de urgência e emergência hospitalar. Eles identificaram como barreira para a implantação da SAE a falta de apoio e interesse por parte da instituição em viabilizar esse método, bem como o despreparo da equipe sobre o tema SAE, a falta de conhecimento como um todo, o 
dimensionamento de pessoal também foi muito relevante na impossibilidade da implementação da SAE na instituição onde o estudo foi desenvolvido (MARIA, 2012).

Estudo mostrou que as dificuldades encontradas pelos enfermeiros foram: a maioria revelou escassez de recursos humanos/sobrecarga de trabalho e elevado número de pacientes, condições inadequadas de trabalho e burocracia relacionada à condições de trabalho (CASAFUS, 2013).

No que se refere à atenção básica, estudos apontam que os enfermeiros ainda demonstram falta de conhecimento sobre a metodologia de trabalho da SAE, eles ainda não a utilizam na sua prática ou a executam de forma parcial, uma vez que poucos profissionais alegaram ter conhecimento suficiente ou bom sobre a SAE, além de acreditarem que este método está voltado para a atenção terciária. Alegam também que a falta de tempo, o número elevado de famílias cadastradas, a falta de recursos humanos e insumos, funções que não são da competência do enfermeiro que o mesmo assume e a falta de apoio da gestão local são dificuldades que inviabilizam a implantação da SAE (KRAUZER, 2015).

De acordo com um estudo realizado na atenção primária, a falta de uma linguagem universal é o que torna mais árduo no processo de enfermagem. Autoras relatam também que a visão do profissional acerca da SAE inserida na atenção primária é limitada, pois eles acreditam que a SAE é restrita à atenção terciária (SOUZA, 2015).

Também foi evidenciado a discordância do aprendizado por parte do profissional na graduação com sua atuação na prática, como também, a abordagem por parte das escolas de graduação de forma insuficiente e/ou incoerente (KRAUZER, 2015).

Há necessidade de investimento em educação permanente e continuada para os profissionais da Atenção Básica, para que os mesmos possam se qualificar e aprimorar seus conhecimentos, a fim de se oferecer uma melhor assistência, pois a falta de conhecimento, de educação permanente e continuada e nomenclaturas utilizadas dificultam a implantação e implementação do SAE (KRAUZER, 2015).

\section{Discussão}

A análise dos artigos revelou que existe uma quantidade insuficiente de profissionais da saúde nas unidades em geral, o que inviabiliza a adequação do sistema de trabalho aos modelos 
propostos para implementação da SAE. Desta forma, ao implementar a SAE a unidade precisa estabelecer padrões de qualidade no serviço prestado, no intuito de adequar a assistência sistematizada eficiente ao padrão que a instituição exige, condizente com o número de recursos humanos e materiais disponíveis (CASAFUS, 2013).

Ao longo da discussão percebe-se que a SAE ainda não é vivenciada eficazmente na prática e, seria inviável sua plena inserção devido a falta de conhecimento dos profissionais, em especial da atenção básica, cuja visão da SAE ainda é limitada por não serem estimulados a trabalharem com esta prática (AMANTE, 2009)

Em contrapartida, existe uma inviabilidade da implantação da SAE na rede terciária, porém, as dificuldades são as mesmas da rede básica, incluindo a falta de apoio e interesse por parte da instituição em viabilizar esse método, profissionais carentes de educação permanente sobre o tema, assim como a ausência de informação relacionada ao uso da SAE (MARIA, 2012).

Entretanto, longe de significar desestímulo, as dificuldades para a implantação sistemática e efetiva da SAE, indicam desafios a estimular a capacidade de reflexão e de ação dos enfermeiros (GARCIA, 2009).

São necessários esforços e debates no meio assistencial, gestão, ensino e controle social, como propõem a Política Nacional de Educação Permanente, para o desenvolvimento de aspectos primordiais na qualificação da assistência em saúde, especialmente no âmbito da atenção básica, como a SAE (KRAUZER, 2015).

Utilizar a SAE como um instrumento metodológico pode, sim, conforme os estudos demonstram, melhorar a assistência; mas a filosofia da Instituição e seus conselhos gestores teriam que se alinhar em operacionalizar uma política de educação permanente (KRAUZER, 2015).

Porém, existem ainda muitas lacunas na produção de conhecimento sobre a SAE, sendo a análise das características administrativas das instituições de saúde, a posição e autonomia da enfermagem, a concentração do poder dentro das instituições e sua interferência na implementação da SAE, aquelas que precisam ser desvendadas para darem suporte aos enfermeiros a fim de avançar na implantação e implementação da SAE nos vários ambientes onde eles atuam (CHAVES, 2009). 


\section{Considerações Finais}

Este estudo evidenciou nos artigos publicados entre 2005 e 2015, contribuições significativas para serem refletidas pelos profissionais de enfermagem, especialmente os enfermeiros, ao apontar dificuldades que vem inviabilizando a implantação e implementação da SAE tanto nas unidades básicas como nas unidades hospitalares.

Dentre as dificuldades foram destacadas aquelas que estão diretamente ligadas a problemas institucionais e pessoais. Assim, percebe-se a necessidade do envolvimento das equipes e da vontade política para se alcançar a meta de implantação da SAE. Para tanto, as questões pessoais como a educação permanente para a equipe de enfermagem e não apenas para os enfermeiros, afinal os técnicos e auxiliares de enfermagem também fazem parte do processo e quanto mais sensibilizados, mais irão contribuir para a implementação da SAE.

Dessa forma, o preparo técnico-científico dos profissionais, as condições institucionais e o envolvimento de toda a equipe de enfermagem tornam-se indispensáveis para implantação e manutenção da SAE. Além disso, com a implantação da SAE, acontecerá uma organização do trabalho na instituição, assim como o reconhecimento que as enfermeiras são possuidores de saberes-fazeres próprios, específicos e inerentes à sua pratica profissional. Para isso, a instituição deve reconhecer as dificuldades apontadas através das percepções destes profissionais e estimar dos aspectos facilitadores, os quais poderão assessorar como indicadores no processo de implantação da SAE.

Portanto, espera-se que este estudo contribua para a reflexão das enfermeiras sobre as dificuldades apontadas pelos estudos analisados, e assim, possam retirar ou contornar tais obstáculos para realmente implementar a SAE em sua completude.

Para tanto, sugerimos que haja uma parceria entre ensino e serviço, enfermeiras, técnicos e auxiliares de enfermagem, serviços de saúde e gestores municipais e estaduais, a fim de falarem uma mesma linguagem, não provocando descompasso entre o ensino e a pratica, e o teórico e o concreto. 


\section{Referências}

ALVES, K.Y.A.; DANTAS, C.N.; SALVADOR, P.T.C.O.; DANTAS, R.A.N. Vivenciando a classificação internacional de práticas de enfermagem em saúde coletiva: relato de experiência. Esc. Anna Nery, vol. 17 (n.2) 381 - 388, 2013.

AMANTE, L.N.; ROSSETTO, A.P.; SCHNEIDER, D.G. Sistematização da Assistência de Enfermagem em unidade de terapia intensiva sustentada pela teoria de wnada horta. Rev Esc Enferm USP, vol. 1 (n.43): 54-64, 2009 .

BARROS, D.G.; CHUIESA, A.M. Autonomia e necessidades de saúde na sistematização da assistência de Enfermagem no olhar da saúde coletiva. Rev. esc. enferm. USP, vol.41: 793-798, 2007.

BRASIL. Conselho Federal de Enfermagem. Resolução COFEN $n^{\circ} 358$, de 15 de outubro de 2009. Dispõe sobre a Sistematização da Assistência de Enfermagem e a implementação do Processo de Enfermagem em ambientes, públicos ou privados, em que ocorre o cuidado profissional de Enfermagem, e dá outras providências. 2016

CASAFUS, K.C.U.; DELL'ACQUA, M.C.Q.; BOCCHI, S.C.M. Entre o êxito e a frustração com a Sistematização da Assistência de Enfermagem. Esc Anna Nery, vol. 2 (n. 17): 313- 321, 2013.

CHAVES L.D. Sistematização da Assistência de Enfermagem: Considerações teóricas e aplicabilidade. São Paulo: Martinari, 2009.

FIGUEIREDO, R.M.; ZEM-MASCARENHAS, S.H.; NAPOLEÃO, A.M.; CAMARGO, A.B. Caracterização da produção do conhecimento sobre sistematização da assistência de enfermagem no Brasil. Rev Esc Enferm USP, vol.40 (n.2): 299-303, 2005.

GARCIA, T.R.; NÓBREGA, M.M.L. Processo de enfermagem: da teoria à prática assistencial e de pesquisa. Esc Anna Nery Rev Enferm, vol. 1 (n.13): 188-193, 2009.

HERMIDA, P.M.V.; ARAÚJO, I.E.M. Sistematização da Assistência de Enfermagem: subsídios para implantação. Rev Bras Enferm, Vol. 5 (n.59): 675-9, 2006.

KRAUZER, I.M.; ADAMY, E.K.; ASCARI, R.A.; FERRAZ, L.; TRINDADE, L.L.; NEISS, M. Sistematização de enfermagem na atenção básica: o que dizem os enfermeiros? Ciencia $Y$ Enfermeria, vol. 21, (n. 2): 31- 38, 2015.

MARIA, M.A.; QUADROS F.A.A.; GRASSI, M.F.O. Sistematização da assistência de enfermagem em serviços de urgência e emergência: viabilidade de implantação. Rev. bras. Enferm, vol.(65): 297-303, 2012. 
MENDES, K.D.S.; SILVEIRA, R.C.C.P.; GALVÃO, C.M. Revisão integrativa: método de pesquisa para a incorporação de evidências na saúde e na enfermagem. Texto contexto - enferm, vol. 17 (n.4): 758-764, 2008.

MIRANDA, L.C.V.; SILVEIRA, R.M.; CHIANCA, M.C.T.; VAZ, F.M.R. Sistematização da Assistência de Enfermagem na atenção primária à saúde: um relato de experiência. Rev de Enferm da UFPE; vol. 1 (n. 7): 295-301, 2013.

SILVA, E.G.C.; OLIVEIRA, V.C.; NEVES, G.B.C.; GUIMARÃES, T.M.R. O conhecimento do enfermeiro sobre a Sistematização da Assistência de Enfermagem: da teoria à prática. Rev Esc Enferm USP, vol. 6 (n.45): 1380- 6, 2011.

SOUZA, N.R.; COSTA, B.M.B.; CARNEIRO, D.C.F.; BARBOSA, H.S.C.B.; SANTOS, I.C.R.V. Sistematização da Assistência de Enfermagem: dificuldades referidas por enfermeiros de um hospital universitário. Revista de enfermagem UFPR, vol 3 (n. 9): 7104-10, 2015.

VARELA, G.C.; FERNANDES, S.C.A. Conhecimentos e práticas sobre Sistematização da Assistência de Enfermagem na estratégia saúde da família. Cogitare Enferm, vol. 1 (n.18): 12430, 2013.

VARELA, G.C.; FERNANDES, S.C.A.; QUEIROZ, J.C.; VIEIRA, N.A.; AZEVEDO, V.R.C. Sistematização as Assistência de Enfermagem na estratégia saúde da família: Limites e possibilidades. Rene, vol. 4 (n.13): 816-24, 2012.

MENEZES, S.R.T.; PRIEL, M.R.; PEREIRA, L.L. Autonomia e vulnerabilidade do enfermeiro na prática da Sistematização da Assistência de Enfermagem. Rev. esc. enferm. USP, vol.45 (n.4): 953-958, 2011.

MEDEIROS, A.L.; SANTOS, S.R.; CABRAL, R.W.L. Sistematização da Assistência de Enfermagem na perspectiva dos enfermeiros: uma abordagem metodológica na teoria fundamentada. Rev. Gaúcha Enferm, vol.33 (n.3): 174-181, 2012.

DINIZ, I.A.; CAVALCANTE, R.B.; OTONI, A.; MATA, L.R.F. Percepção dos enfermeiros gestores da atenção primária sobre o processo de enfermagem. Rev. Bras. Enferm, vol.68 (n.2): 206-213, 2015.

\section{Como citar este artigo (Formato ABNT):}

GOMES, Renara Meira; TEIXEIRA, Lucas S.; SANTOS, Maria da Conceição Q. dos ; SALES, Zenilda N.; LINHARES, Eliane F.; SANTOS, Kay A. Sistematização da assistência de enfermagem: revisitando a literatura brasileira. Id on Line Rev.Mult. Psic., 2018, vol.12, n.40, p.995-1012. ISSN: 19811179 .

Recebido: 25/05/2018

Aceito 28/05/2018 